\title{
Laparoscopic myomectomy in a patient with laparoscopic vaginoplasty (modified Davydov) and a review of the literature
}

\author{
Esengül Türkyılmaz, ${ }^{1}$ Mesut Öktem, ${ }^{2}$ Ahmet Erdem² \\ 'Department of Gynecology and Obstetrics, Ataturk Training and Research Hospital, Ankara, Turkey \\ 2Department of Gynecology and Obstetrics, Gazi University Faculty of Medicine, Ankara, Turkey
}

\begin{abstract}
Mayer-Rokitansky-Kuster-Hauser (MRKH) syndrome is characterized by congenital absence of the uterus and vagina, or uterus may be rudimentary. Coexistence of myoma uteri with MRKH syndrome is possible. The case presented in this study is the 18th report in the literature. Moreover, it is the first with coexistent skeletal system anomalies, left pelvic renal ectopia, and leiomyoma of the rudimentary uterus. Review of English-language medical literature revealed that coexistence of uterine leiomyoma and MRKH syndrome is very rare. However, if a patient with MRKH syndrome presents with a pelvic mass, the possibility of leiomyoma should be considered.
\end{abstract}

Keywords: Davydov operation; Mayer-Rokitansky-Kuster-Hauser syndrome; myoma uteri.

\section{Introduction}

Mayer-Rokitansky-Kuster-Hauser (MRKH) syndrome is characterized with the congenital absence of uterus and vagina. While uterus may be rudimentary, fallopian tubes and ovaries are present. Secondary sexual characteristics are normally developed. Anomalies of the urinary tract and skeletal system may accompany this syndrome.

Coexistence of uterine myoma and Rokitansky syndrome was first reported in 1977. ${ }^{[1]}$ The case presented in this study is the eighteenth report in the literature. Moreover, it is the first one with coexistent skeletal system anomalies, left pelvic renal ectopia, and leiomyoma of the rudimentary uterus.

\section{Case Report}

The 24-year-old, married patient was diagnosed with MRKH syndrome at the age of 18 when she first applied to the hospital with the complaint of never having had menstruation. During her diagnostic laparoscopy, she was found to have a rudimentary uterus, bilateral and normal appearing ovaries and fallopian tubes, and left renal pelvic ectopia. Her gynecologic examination revealed a blind vaginal pouche of $1 \mathrm{~cm}$ in length and secondary sexual characteristics were fully developed. The karyotype was 46, XX.

Her presenting complaint when she applied to our clinic in 2009 was not being able to have sexual intercourse de- 
spite two years of marriage. Transabdominal ultrasonography revealed a rudimentary uterus and bilateral normal ovaries. Left renal pelvic ectopia was diagnosed during intravenous pyelography.Posterior arcus fusion defect in sacral vertebras were identified. Davydov operation was planned for the treatment of vaginal agenesis.

During the operation, an eight $\mathrm{cm}$ sized mass originating from the rudimentary horn of the uterus was seen. Laparoscopic excision of the mass was carried out. Bilateral ovaries were normal in appearance. Vesicorectal space was dissected untilperitoneum was visualized. Peritoneal edges and perineal epithelium were approximated with sutures. Afterwards, peritoneum, which would be the vag- inal cuff, was saturated laparoscopically. At the end of the operation, a rigid stent soaked with vaseline was put into the newly created vagina. The pathological report of the excised mass was in accordance with uterine leiomyoma. Vaginal dilator was taken out on the postoperative fifth day and the patient was discharged on the postoperative sixth day.

\section{Discussion}

Diagnosis of MRKH syndrome is generally made in adolescence during the work up of primary amenorrhea. Vaginal reconstructive operations are carried out in patients with this diagnosis to improve penetration during sexual

\section{Table 1. Characteristics of patients with MRKH syndrome and coexisting leiomyoma}

\begin{tabular}{|c|c|c|c|c|}
\hline Case number & $\begin{array}{l}\text { Detecting age of } \\
\text { myoma uteri }\end{array}$ & Complaint & $\begin{array}{l}\text { Type of operative procedure } \\
\text { for vaginal agenesis }\end{array}$ & $\begin{array}{l}\text { Dimension of } \\
\text { myoma uteri }\end{array}$ \\
\hline Case I 1977[1] & Data not available & & & \\
\hline Case II 1978[10] & & & McIndoe's procedure & Large leiomyoma \\
\hline Case III 1988 ${ }^{[15]}$ & 32 & $\begin{array}{l}\text { Lower abdominal } \\
\text { pain and bloating }\end{array}$ & Mclndoe's procedure & $100 \times 8.5 \mathrm{~mm}$ \\
\hline Case IV $1988^{[21]}$ & & & Vaginal dilatation & $4 \mathrm{~cm}$ \\
\hline Case V 1999:16] & & $\begin{array}{l}\text { Episodic pelvic pain and } \\
\text { urinary frequency }\end{array}$ & No operation & $\begin{array}{l}62 * 62 * 63 \text { mitotically } \\
\text { active myoma }\end{array}$ \\
\hline Case VI $2000^{[2]}$ & 27 & Pelvic pain & Mclndoe's procedure & $49 \times 46 \times 44 \mathrm{~mm}$ \\
\hline Case VII $2000^{[13]}$ & 36 & Pelvic pain & Vaginopoiesis & $85 \mathrm{~mm}$ \\
\hline Case VIII $2000^{[22]}$ & Data not available & & & \\
\hline Case IX $2002^{[17]}$ & 52 & Low abdominal pain & No operation & $12 \times 12 \times 8.5$ \\
\hline Case X 2003[12] & 42 & Deep dyspareunia & $\begin{array}{l}\text { Vaginoplasty using } \\
\text { amniotic membranes }\end{array}$ & $100 \mathrm{~mm}$ \\
\hline Case XI 2003[18] & 42 & Lower abdominal pain & $\begin{array}{l}\text { Creatsas modification of } \\
\text { Williams' vaginoplasty }\end{array}$ & $59 \times 55 \mathrm{~mm}$ \\
\hline Case XII $2003^{[18]}$ & 38 & $\begin{array}{l}\text { A mass in the area } \\
\text { of left adnexa }\end{array}$ & $\begin{array}{l}\text { Creatsas modification of } \\
\text { Williams' vaginoplasty }\end{array}$ & $48 \times 36 \mathrm{~mm}$ \\
\hline Case XIII $2003^{[23]}$ & 55 & $\begin{array}{l}\text { The first one torsion of } \\
\text { myoma uteri, second one } \\
\text { episodic pelvic pain }\end{array}$ & $\begin{array}{l}\text { Deepen of the natural recess } \\
\text { between bladder and rectum }\end{array}$ & $\begin{array}{c}\text { The first one } 11 \mathrm{~cm} \text {, } \\
\text { the second one } \\
10 \times 7.5 \mathrm{~cm}\end{array}$ \\
\hline Case XV 2006 ${ }^{[24]}$ & 41 & $\begin{array}{l}\text { Cyclic lower abdominal } \\
\text { pain }\end{array}$ & $\begin{array}{l}\text { Vaginal reconstructive } \\
\text { procedure }\end{array}$ & $56 \times 40 \mathrm{~mm}$ \\
\hline Case XVI 2008 & 47 & $\begin{array}{l}\text { Lower abdominal pain, } \\
\text { pelvic tumescence }\end{array}$ & & $50 \mathrm{~mm}$ \\
\hline Case XVII 2009 ${ }^{[14]}$ & 39 & Asymptomatic & No vaginal reconstruction & 90 mm \\
\hline $\begin{array}{l}\text { Case XIX } 2009 \\
\text {-our case }\end{array}$ & 24 & $\begin{array}{l}\text { Failure of sexual } \\
\text { relationship }\end{array}$ & $\begin{array}{l}\text { Laparoscopic approach } \\
\text { of davydov }\end{array}$ & $80 \times 70 \mathrm{~mm}$ \\
\hline Case XX $2012^{[20]}$ & 28 & $\begin{array}{l}\text { Mass and acute } \\
\text { abdominal pain }\end{array}$ & Unknown & $10 \times 15 \mathrm{~cm}$ \\
\hline Case XXI $2012^{[20]}$ & 34 & $\begin{array}{l}\text { Primary amenorrhea, } \\
\text { infertility }\end{array}$ & Unknown & $6 \mathrm{~cm}$ \\
\hline Case XXII 2013 $3^{[19]}$ & 35 & $\begin{array}{l}\text { Mass and pain, } \\
\text { primary amenorrhea }\end{array}$ & & $25 \times 18 \times 12 \mathrm{~cm}$ \\
\hline
\end{tabular}


intercourse and help these patients with their psychological conditions. Since bilateral ovaries, fallopian tubes, and two uterine remnants of various sizes exist in patients with this syndrome, pathologies of these structures are possible. In the literature regarding $\mathrm{MRKH}$, there are case reports of leiomyomas originating from rudimentary horns in patients presenting with pelvic pain, adenomyosis, degenerated leiomyomas, ovarian carcinoma in two patients, ovarian dysgerminoma, immature teratoma of the ovary in a four year old girl and ovarian endodermal sinus tumor. ${ }^{[2-7]}$ Since ovarian steroidogenesis continues in these patients, they should be followed up for genital neoplasms showing estrogenic activity. Complications due to pathologies as the degeneration of a leiomyoma or torsion of an ovarian cyst should be kept in mind.

Table 1 shows the characteristics of MRKH cases with leiomyomas and it can be seen that most cases presented many years after vaginal reconstruction. The leiomyoma in this case was diagnosed and excised during laparoscopic davydov operation. Magnetic resonance imaging is very helpful in identifying ovaries, rudimentary uterus as well as accompanying pelvic and skeletal anomalies in related body regions in these patients. The incidence of upper urinary tract anomalies coexisting MRKH syndrome is $30-40 \%$. The most common accompanying anomalies are renal agenesis and pelvic renal ectopia. ${ }^{[8]}$ This case report is the first in the literature presenting leiomyoma originating from a rudimentary uterine horn with skeletal system defect and renal pelvic ectopia in a patient with MRKH syndrome. In cases of leiomyoma arising from a rudimentary horn, myomectomy with excision of the horn is indicated..$^{[9,10]}$ However, since the leiomyoma was pedunculated in this case, only myomectomy was performed. Myomectomy can be done with laparotomy or laparoscopy ${ }^{[11-20]}$ Since laparoscopy had initially been used in this case, myomectomy was also laparoscopically carried out.

Various vaginal reconstruction methods are defined for patients with MRKH syndrome. The most popular of these are the Frank nonsurgical technique, the Williams vaginoplasty and its Creatsas modification, the Vechietti operation, and laparoscopic davydov operation used in this case. On the postoperative sixth week, the vaginal length in this case was $7-8 \mathrm{~cm}$. Two years after the operation, the vaginal length and width was 6 and $2 \mathrm{~cm}$, respectively. The patient reported to be able to have sexual intercourse.

Coexistence of uterine leiomyoma and MRKH syndrome is very rare. Therefore, it may not be possible to identify myoma before the operation. However, if a patient with MRKH syndrome presents with a pelvic mass, the possibility of a leiomyoma should be considered.

\section{References}

1. Beecham CT, Skiendzielewski J. Myoma in association with Mayer-Rokitansky-Kuester syndrome. Am J Obstet Gynecol 1977;129:346-8.

2. Enatsu A, Harada T, Yoshida S, Iwabe T, Terakawa N. Adenomyosis in a patient with the Rokitansky-Kuster-Hauser syndrome. Fertil Steril 2000;73:862-3.

3. Hsu SC, Tsai EM, Wu CH, Lee JN. A mullerian duct remnant myoma misdiagnosed as ovarian cancer in a woman with vaginal agenesis-a case report. Kaohsiung J Med Sci 1999;15:110-2.

4. Ghirardini G, Magnani A. Mayer-Rokitansky-Küster-Hauser syndrome and ovarian cancer. Report of a case. Clin Exp Obstet Gynecol 1995;22:247-8.

5. Mishina A, Gladun E, Petrovici V, lakovleva I. Ovarian dysgerminoma in Mayer-Rokitansky-Küster-Hauser syndrome. Eur J Obstet Gynecol Reprod Biol 2007;131:105-6.

6. Tsaur GT, Lee MH, Su SL, Wu MJ, Huang TW. Mayer-Rokitansky-Kuster-Hauser syndrome with immature teratoma of the ovary at age 4 years. Gynecol Oncol 1995;56:456-9.

7. Koonings PP, al-Marayati L, Schlaerth JB, Lobo RA. Mayer-Rokitansky-Kuster-Hauser syndrome associated with endodermal sinus tumor of the ovary. Fertil Steril 1991;56:5778.

8. Basile C, De Michele V. Renal abnormalities in Mayer-Rokitanski-Küster-Hauser syndrome. J Nephrol 2001;14:316-8.

9. Saadi N, Outifa M, Belghiti L, Kharmach M, Chraibi C, el Fehri $S$, et al. Uterine leiomyoma in a patient with Rokitansky-Kuster-Hauser syndrome. Report of a case. J Gynecol Obstet Biol Reprod (Paris) 1999;28:165-7.

10. Farber M, Stein A, Adashi E. Rokitansky-Kuster-Hauser syndrome and leiomyoma uteri. Obstet Gynecol 1978;51:70s-73s.

11. Connell R, Cutner A, Creighton S. Laparoscopic removal of an ectopic uterus in a patient with Mayer-Rokitansky-Küster-Hauser syndrome. J Obstet Gynaecol 2000;20:97.

12. Jadoul P, Pirard C, Squifflet J, Smets M, Donnez J. Pelvic mass in a woman with Mayer-Rokitansky-Kuster-Hauser syndrome. Fertil Steril 2004;81:203-4.

13. Tsin DA, Waters TK, Granato RC. Laparoscopic myomectomy in a patient with Mayer-Rokitansky-Kuster-Hauser syndrome. J Am Assoc Gynecol Laparosc 2000;7:411-3.

14. Lanowska M, Favero G, Schneider A, Köhler C. Laparoscopy for differential diagnosis of a pelvic mass in a patient with Mayer-Rokitanski-Küster-Hauser (MRKH) syndrome. Fertil Steril 2009;91:931.e17-8.

15. Metzger DA, Massad LS, Piscitelli JT. Leiomyoma in a müllerian remnant. A case report. J Reprod Med 1988;33:246-8.

16. Forsnes $\mathrm{EV}$, Derrough KR, O'Donoghue M. A mitotically active myoma in Rokitansky-Küster-Hauser syndrome. Obstet Gy- 
necol 1999;94:862.

17. Yan CM, Mok KM. Uterine fibroids and adenomyosis in a woman with Rokitansky-Kuster-Hauser syndrome. J Obstet Gynaecol 2002;22:561-2.

18. Deligeoroglou E, Kontoravdis A, Makrakis E, Christopoulos P, Kountouris A, Creatsas G. Development of leiomyomas on the uterine remnants of two women with Mayer-Rokitansky-Küster-Hauser syndrome. Fertil Steril 2004;81:1385-7.

19. Rawat KS, Buxi T, Yadav A, Ghuman SS, Dhawan S. Large leiomyoma in a woman with Mayer-Rokitansky-Kuster-Hauser syndrome. J Radiol Case Rep 2013;7:39-46.

20. Fletcher HM, Campbell-Simpson K, Walcott D, Harriott J. Müllerian remnant leiomyomas in women with Mayer-Rokitansky-Küster-Hauser syndrome. Obstet Gynecol 2012;119:483-5.

21. Powell B, Cunnane MF, Dunn LK, Corson SL. Leiomyoma uteri in a rudimentary uterine horn in a woman with the Rokitansky-Kuster-Hauser syndrome. A case report. J Reprod Med 1988;33:493-4.
22. Dandu S, Jones SE, Okeahialam MG. Rokitansky-Kuster-Hauser syndrome associated with chromosomal abnormality and fibroid arising from the rudimentary uterine horn. J Obstet Gynaecol 2000;20:98.

23. Galajdova L, Verbeken K, Dhont M. Recurrent multiple leiomyomata in a patient with Mayer-Rokitansky-Küster-Hauser syndrome. J Obstet Gynaecol 2003;23:448-9.

24. Al-Fadhli R, Tulandi T. A rare case of completely separated rudimentary uterine horns with myoma and adenomyosis. J Minim Invasive Gynecol 2006;13:86-7.

25. Papa G, Andreotti M, Giannubilo SR, Cesari R, Ceré I, Tranquilli AL. Case report and surgical solution for a voluminous uterine leiomyoma in a woman with complicated Mayer-Rokitansky-Küster-Hauser syndrome. Fertil Steril 2008;90:2014. e5-6.

26. Lamarca $M$, Navarro $R$, Ballesteros ME, García-Aguirre $S$, Conte MP, Duque JA. Leiomyomas in both uterine remnants in a woman with the Mayer-Rokitansky-Küster-Hauser syndrome. Fertil Steril 2009;91:931.e13-5. 